\title{
THE RELATIONSHIP BETWEEN BETA ENDORPHINS AND EMOTIONAL STATE IN PHYSICALLY ACTIVE INDIVIDUALS AGED 45-55 (A REPORT ON A PILOT STUDY)
}

\author{
IEVA KUNDZIN, ${ }^{1}$, JURIS GRANTS ${ }^{2}$ \\ Latvian Academy of Sport Education, Department of Anatomy ${ }^{1}$, Department of Skiing ${ }^{2}$ \\ Mailing address: Ieva Kundziņa, Latvian Academy of Sport Education, Department of Anatomy, \\ 333 Brivibas street, LV-1006 Riga, tel.: +371 29109865, fax: +371 67543480, \\ e-mail: ieva.kundzina@lspa.lv
}

\begin{abstract}
Introduction. This sports-science-related article heavily relies on studies that have reported an increase in beta-endorphin $(\beta-E P)$ concentration in plasma in response to physical activity. It examines the psychological and physiological effects of physical activity and exercise and reports on a research-experiment-based, endorphin-hypotheses-related pilot study aimed at exploring mood-related $\beta$-EP effects occurring in physically active male and female individuals aged 45-55 in response to physical load. Material and methods. Six 45 to 55-year-old individuals ( 3 males and 3 females) rated as exhibiting moderate and high levels of physical activity in sport's laboratory. International Physical Activity Questionnaire (IPAQ) was used to establish physical activity level. For facial expression analysis a short interview was applied, using software "FaceReader 3.0" (FR). As a load test a veloergometer exercise test was used, and Beta-endorphin ( $\beta$-EP) levels were measured from venous blood. Results. The findings demonstrated an increase in $\beta$-EP levels in $50 \%$ of the subjects. No positive relation between $\beta$-EP increase and happiness has been observed. In four subjects an increase in disgust was observed due to the laboratory conditions. Five minutes after the load test FR data recorded the reduction or disappearance of negative emotions for all research subjects. Conclusions. Further investigation into the relationship of plasma levels of $\beta$-EP and the emotional state of the individual involved in physical activities is needed. This necessitates a further insight into how exercise-elevated endorphins ( $\beta$-EP) affect mood state outside laboratory conditions. Therefore, a further investigation of people involved in physical recreation activities outdoors is envisaged.
\end{abstract}

Key words: plasma beta-endorphins, emotional expressions, physical load

\section{Introduction}

Endorphins were discovered in the mid-1970s. Endorphins are released from the pituitary gland into the circulatory system $[1,2,3]$. In the literature there are a lot of different studies where researchers show relations between endorphins and a number of psychological and adaptive factors such as analgesia, stress, emotions, motivation, behavior, euphoria and mental well-being $[3,4,5,6,7]$. There are also studies examining the relationship between vigorous exercise and blood plasma endorphin levels; some researchers indicate a significant increase in endorphin levels during or after exercise, while others do not [3, 8, $9,10]$. The present article reviews the relationship between beta endorphins and emotional state in response to physical activity.

\section{Material and methods}

The pilot research took place on February 21 and March 1, 2013 in the locally available sports laboratory "VIP Sport" in Riga. The subjects had been selected according to the following criteria: age, gender and physical activity level, the latter having been judged according to the results of the short version of the International Physical Activity Questionnaire (IPAQ) administered beforehand. Six 45 to 55-year-old individuals (3 males and 3 females) exhibiting moderate and high levels of physical activity took part in the research experiment. First, data regarding the participants' emotional state was recorded.
Subjective data was gathered by interviewing the subjects regarding the feelings they were experiencing at the moment and asking them to speculate about their reasons for being in a particular emotional state (the interview's questions were: "How do you feel?" and "What are the main reasons of your feelings?"). The interview was required for assessment of emotions using facial expression analysis software: FaceReader (FR). Objective data was gathered by evaluating each subject's emotional state with the help of FaceReader (FR). As a complete facial expression analysis program, it is the world's first tool capable of automatically analyzing facial expressions. It recognizes facial expressions with an accuracy of $89 \%$. The version which was used was FaceReader 3 [11]. By allowing the user to evaluate a person's emotional state in terms of 6 basic emotional states "happy”, "sad”, "angry”, "disgusted", "scared”, "surprised” (the two additional options being "neutral" and "other") - it provided an objective assessment of a subject's emotional state. Emotions like "neutral" and "other" were not analyzed. Five minutes after the facial expression analysis, blood samples were drawn from the median cubital vein. After the drawing of venous blood samples, a test on the veloergometer followed. It was a maximal physical load test without a rest period with the load being increased after every 3 minutes and an average duration reaching 28 minutes. Five minutes after the load test the pre-test procedures - interviewing the participants, applying the Face Reader and drawing the blood samples - were repeated to collect the post-test data so that conclusions could be drawn about the psychological and physiological load-effected manifesta- 
tions in the research subjects. Post-test procedures were performed in exactly the same conditions as before the veloergometer test. The vacutainers containing pre- and post-test blood samples were delivered to the laboratory, where plasma $\beta$-EP endorphin levels were determined by means of a standard radioimmunoassay ELISA kit [12]. In analyzing the research results, gender- and menstrual-cycle-influenced circulating endorphin concentration was not considered. $\beta$-EP levels in women at rest may be slightly lower than in men regardless of the timing of women's menstrual cycle, but there is no statistical significance of physical-load-affected $\beta$-EP level response related to gender [13].

\section{Results}

The aim of the study was to explore $\beta$-EP effects on the human body, in particular, $\beta$-EP-affected changes in the emotional state of physically active individuals, both male and female, aged 45 to 55 involved in a veloergometer test. To achieve this aim, plasma $\beta$-EP levels were tested and a facial expressions analyzer, FR, was used.

The blood test results showed a plasma $\beta$-EP increase in 3 subjects (JG $+33.74 \%$, IB $+17.84 \%$, MP $+38.79 \%$ ) and a decrease in other 3 subjects (IK 21.17\%, JP 16.8\%, IZ 7.87\%) (fig. 1).



Figure 1. Changes in plasma $\beta$-EP levels after veloergometer test

Before the load test, the lowest plasma $\beta$-EP level was diagnosed for subject JG - $16.3 \mathrm{ng} / \mathrm{ml}$ and the highest for subject IZ $35.6 \mathrm{ng} / \mathrm{ml}$ (fig. 2).

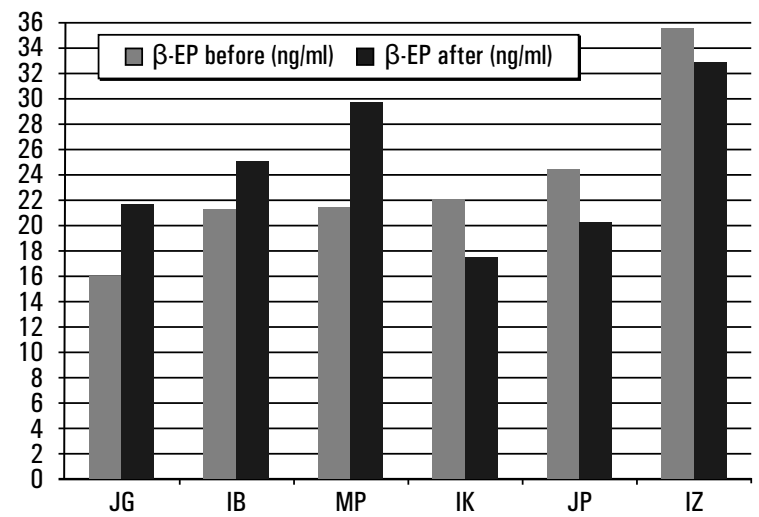

Figure 2. Plasma $\beta$-EP levels before and after veloergometer test $(\mathrm{ng} / \mathrm{ml})$
To assess subjects' emotions before and 5 minutes after the veloergometer test "FaceReader 3.0", a facial expression analysis program, was used. To aid in identifying emotions with FR, a short interview was conducted consisting of two questions: "How do you feel?" and "What are the main reasons of your feelings?”.

Summarizing positive emotions (happiness and surprise) FR data showed an increase in positive emotions for four subjects (JG +47\%; IB +14\%; JP and IZ +1\%). Only for one subject, IK, were positive emotions decreased: by $3 \%$ (fig. 3 ). In examining positive emotions separately, the results showed an increase in happiness of $20 \%$ and a decrease in surprise of $23 \%$ (fig. 4 and 5).

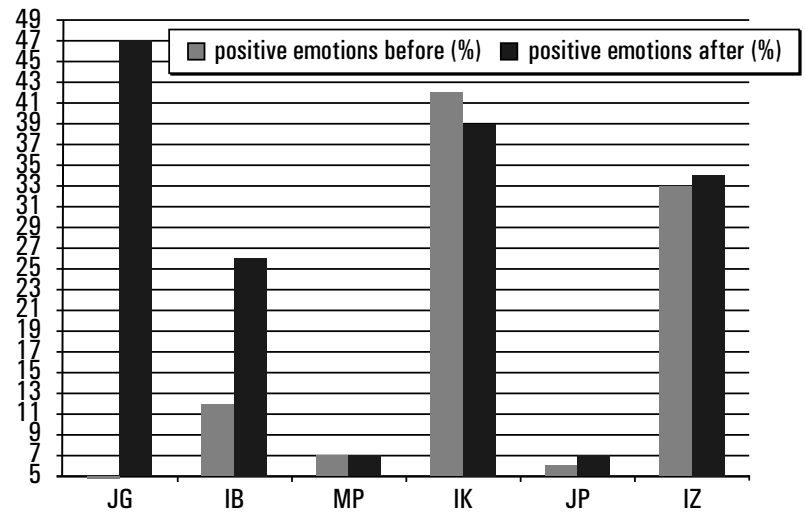

Figure 3. Positive emotions for all subjects before and after veloergometer test (\%)

In analyzing data concerning the effect of the physical load on the happiness level, an increase was observed for three subjects (JG +28\%; IK +20\%; IZ +13\%). For the other three subjects FR diagnosed happiness neither before nor after the veloergometer test (fig. 4).

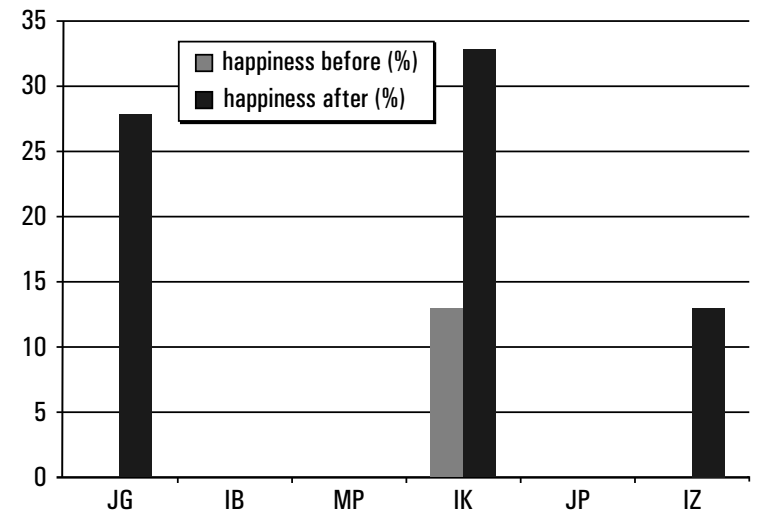

Figure 4. Percentage level of happiness for all subjects before and after veloergometer test

The FR data indicated an increase in emotions like surprise for three subjects (JG +19\%; IB +14\%; JP +1\%). For subject MP, the level of surprise did not change and for subjects IK and IZ the surprise decreased by $-23 \%$ and $-12 \%$ respectively (fig. 5). 


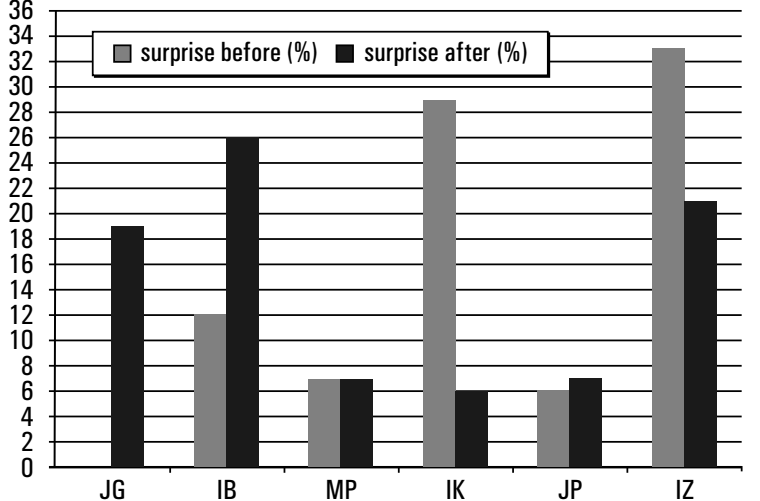

Figure 5. Percentage level of surprise for all subjects before and after veloergometer test

In summarizing all FR data for all six subjects it becomes clear that almost all of them show a reduction in negative emotions (fright, sadness, anger, disgust) after the veloergometer test. Only for one subject, MP, did facial expression analysis software show an increase in negative emotions of $15 \%$ (fig. 6). Separate analysis showed an increase in negative emotions for subject MP: a pronounced, $34 \%$ increase in disgust (fig. 7), which is the main reason for the high overall level of negative emotions.

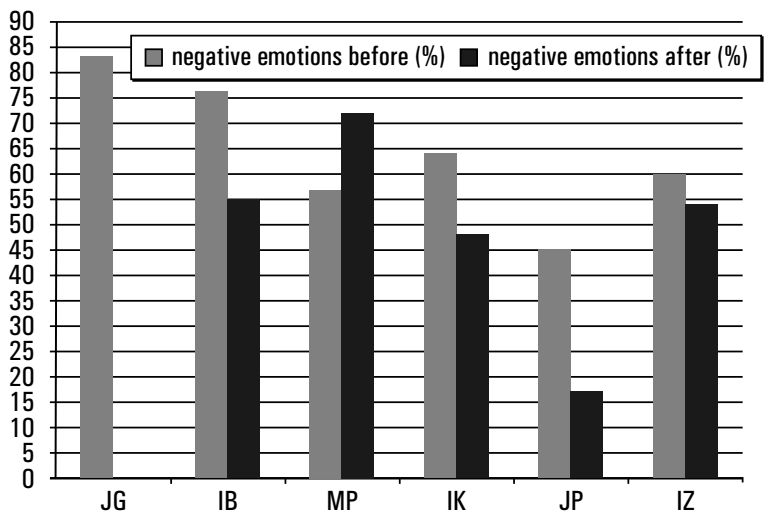

Figure 6. Negative emotions for all subjects before and after veloergometer test $(\%)$

An analysis of FR data on negative emotions - fright, sadness, anger and disgust - indicated a decrease in fright for subjects IB -25\%; IK -32\%; IZ -14\%. For subject JG fright was observed to disappear after the veloergometer test, and for subjects MP and JP fright was not observed at all (fig. 7).



Figure 7. Percentage level of fright for all subjects before and after veloergometer test

FR data on negative emotions like sadness showed an increase for only one subject - IZ (+5\%). After the load test, sadness was observed to dissapear for subject JG. For subject JP, Face Reader observed no sadness at all. For subjects IB, MP and IK data showed a decrease in sadness by $-7 \%,-19 \%$ and $-1 \%$, respectively (fig. 8).

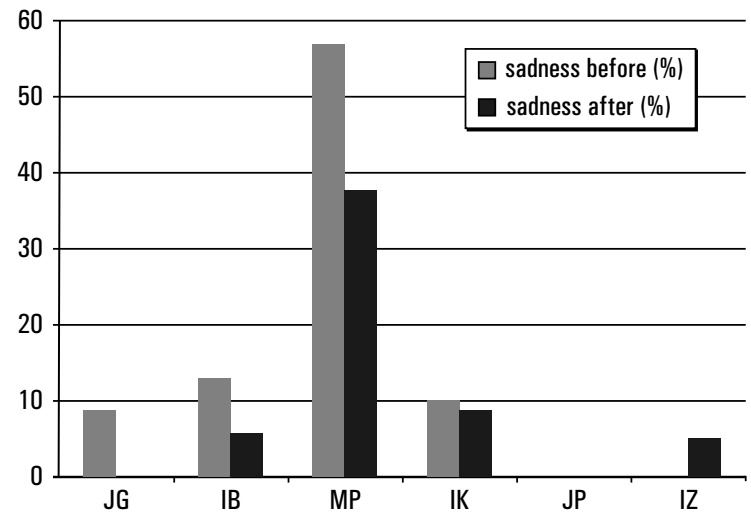

Figure 8. Percentage level of sadness for all subjects before and after veloergometer test

After the physical load test, FR detected changes in anger for only two subjects - JG and JP. For subject JP, anger decreased by $28 \%$, while for subject JG it disappeared altogether (fig. 9).



Figure 9. Percentage level of anger for all subjects before and after veloergometer test 
After the veloergometer tests, FR observed an increase in disgust for four subjects - IB +11\%; MP + $34 \%$; IK + $7 \%$ and IZ $+3 \%$. Only for one subject, JG, did Face Reader diagnose the disappearance of disgust, while for another subject, JP, this emotion was not observed at all (fig. 10).

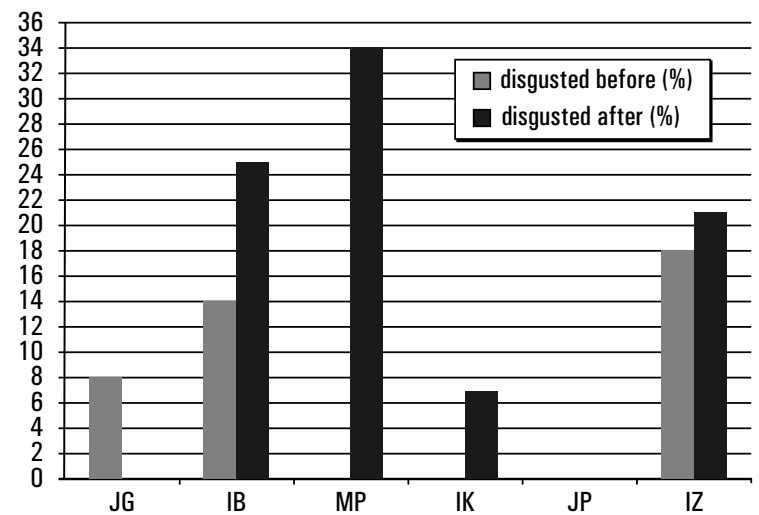

Figure 10. Percentage level of disgust for all subjects before and after veloergometer test

\section{Discussion}

The literature abounds in clinical research studies which measure endorphin levels before and after physical activity. The results obtained are conflicting: while some report a significant increase in endorphin levels, others do not. A number of findings support the idea that endorphins may be released as a result of exercising with an intensity of at least $60 \% \mathrm{VO}_{2 \max }$ for a specific amount of time [14]. Observations show that acute positive changes in mood after physical activity might be related to an increase in endorphin level $[3,4,5,6,7]$. Our research demonstrates that different changes in emotional state occur in both men and women due to a physical load. In analyzing the research results, gender- and menstrual-cycle-influenced circulating endorphin concentration was not considered. To summarize all FR data for all the subjects, each subject showed a reduction in at least one negative emotion after the veloergometer test. For four pilot research subjects, FR observed an increase in disgust after the veloergometer tests, which can be attributed to laboratory conditions. The FR data collected prior to the load test indicate that every research subject experiences at least one of the negative emotions - fright, sadness or anger - while the data recorded 5 minutes after the load test show that this kind of emotion either becomes less pronounced or disappears. After the physical load test an increased percentage of sadness was detected by FR only for one subject and increase was insignificant - only for $5 \%$. An increase in happiness after the physical load test was observed for three subjects. However, a clear relation between plasma $\beta$-EP level and happiness was not found, because a relation between plasma $\beta$-EP release $(+33.74 \%)$ and increased happiness $(+28 \%)$ was found for only one subject found.

\section{Conclusions}

The presented investigation of both men and women found changes in emotional state after a veloergometer test, with five of six subjects demonstrating a decrease in negative emotions (anger, sadness, fright, disgust). An obvious relation between plasma levels of $\beta$-EP and changes in six basic emotions detected by "FaceReader 3.0", a facial analysis program, was not found.
Further investigation is needed regarding the relationship between plasma levels of $\beta$-EP and the emotional state of the individual involved in physical activities. To determine the role of beta-endorphin effect on psychological well-being in exercise, the authors are going to perform research outdoors using different physical recreation activities involving a defined heart rate and a specific amount of time.

\section{Literature}

1. Mousa S.A., Shakibaei M., Sitte N., Schäfer M., Stein C. (2004). Subcellular pathways of beta-endorphin synthesis, processing, and release from immunocytes in inflammatory pain. Endocrinology 145(3), 1331-41.

2. Bender T., Nagy G., Barna I., Tefner I., Kadas E., Geher P. (2007). The effect of physical therapy on beta-endorphin levels. European Journal of Applied Physiology 100, 371-382. DOI: 10.1007/s00421-007-0469-9.

3. Biddle S.J.H., Mutrie N. (2007). Psychology of physical activity determinants, well-being and interventions ( $2^{\text {nd }}$ edition). London: Routledge.

4. Peluso M., Andrade L. (2005). Physical activity and mental health: the association between exercise and mood. Clinics 60(1), 61-70.

5. Daniel M., Martin A. (1992). Opiate receptor blockade by naltrexone and mood state after acute physical activity. British Journal of Sports Medicine 26(2), 111-115.

6. Kenneth R. (1999). The influence of physical activity on mental well-being. Public Health Nutrition 2(3a), 411-418.

7. Landers D.N. (1997). The influence of exercise on mental health. PCPFS Research Digest 2(12).

8. Boecker H., Othman A., Mueckter S., Scheef L., Pensel M., Daamen M. et al. (2010). Advocating neuroimaging studies of transmitter release in human physical exercise challenges studies. Journal of Sports Medicine 1, 167-175.

9. Leuenberger A. (2006). Endorphins, exercise, and addictions: A review of exercise dependence. The Premier Journal for Undergraduate Publications in the Neurosciences 3, 1-9.

10. Pierce E., Eastman N., Tripathi H., Olson K., Dewey W. (1993). ß-Endorphin response to endurance exercise: relationship to exercise dependence. Perceptual and Motor Skills 77(3), 767-770.

11. Kuilenburg H., Uyl M. (2005). The FaceReader: Online facial expression recognition. In $5^{\text {th }}$ International Conference on Methods and Techniques in Behavioral Research "Measuring Behavior 2005”, 30 August - 2 September 2005 (pp. 589-590). Wageningen: Noldus Information Technology. Retrieved from http://www.vicarvision.nl/pub/fc_denuyl_and_vankuilenburg 2005.pdf.

12. Kamiya Biomedical Company. Human $\beta$ Endorphin (BEP) ELISA kit. Instruction manual. Cat. No. KT-53389.

13. Goldfarb A.H., Jamurtas A.Z., Kamimori G.H., Hegde S., Otterstetter R., Brown D.A. (1998). Gender effect on beta-endorphin response to exercise. Medicine and Science in Sports and Exercise 30(12), 1672-1676.

14. Langenfeld M., Hart L., Kao P. (1987). Plasma endorphin responses to one hour bicycling and running at $60 \% \mathrm{VO}_{2 \max }$. Medicine and Science in Sports 19, 83-86.

Submitted: March 6, 2014

Accepted: June 30, 2014 